\title{
Practice points for ophthalmologists from the 2020 British Society for Rheumatology Giant Cell Arteritis guidelines
}

\author{
Susan P. Mollan $\mathbb{D}^{1} \cdot$ Olivia Grech ${ }^{2,3} \cdot$ Eoin O'Sullivan $^{4} \cdot$ Sarah L. Mackie $\mathbb{1}^{5,6}$ \\ Received: 13 June 2020 / Revised: 26 June 2020 / Accepted: 8 July 2020 / Published online: 16 July 2020 \\ (c) The Royal College of Ophthalmologists 2020
}

All ophthalmologists are aware that giant cell arteritis (GCA) is a major cause of sudden permanent loss of vision. However, the diagnosis and management of GCA can be challenging in the busy eye out-patient clinic. GCA poses some major difficulties, even for the experienced clinician. The clinical history may be non-specific, with the onset of symptoms being insidious [1]. Furthermore, those with cranial GCA may report no systemic symptoms (the true occult GCA) [2]. Immediate investigations can be conflicting, particularly as inflammatory markers are nonspecific and may be low to normal in cranial only disease $[3,4]$. Arranging a temporal artery biopsy (TAB) promptly may not be easy and interpretation is not always straightforward [5, 6]. Finally managing the patient long-term on glucocorticoids, particularly in the face of co-morbid disease or glucocorticoid-induced diabetes and hypertension, can be difficult [7].

There have been major developments in GCA [1, 8] and now as a nation we are investigating more suspected GCA annually [9]. The British Society of Rheumatology (BSR) have published timely guidance $[10,11]$ to reflect these

Susan P. Mollan

Susan.mollan@uhb.nhs.uk

1 Birmingham Neuro-Ophthalmology Unit, University Hospitals Birmingham NHS Foundation Trust, Birmingham B15 2TH, UK

2 Metabolic Neurology, Institute of Metabolism and Systems Research, College of Medical and Dental Sciences, University of Birmingham, Birmingham B15 2TT, UK

3 Centre for Endocrinology, Diabetes and Metabolism, Birmingham Health Partners, Birmingham B15 2TH, UK

4 Department of Ophthalmology, Kings College Hospital, London, UK

5 Leeds Institute of Rheumatic and Musculoskeletal Medicine, University of Leeds, Leeds, UK

$6 \quad$ NIHR Leeds Biomedical Research Centre, Leeds Teaching Hospitals NHS Trust, Leeds, UK advances following their previous guideline [12] and they recommend a change to our routine clinical practice.

The BSR is accredited by the National Institute for Health and Care Excellence, and commissioned this update in 2014. The guideline group involved patients, methodologists and experts in GCA, from rheumatology, ophthalmology and primary care. They developed population, intervention comparator, and outcome questions to form the basis of three systemic literature reviews (SLR). The SLRs covered diagnostic imaging tests, management strategies and prognostic outcomes. The quality of evidence was assessed set out by Grading of Recommendations Assessment, Development and Evaluation methodology [13].

\section{Recommendations for referral to hospital services}

Rapid access pathways have been set up in a number of centres that use ultrasound in order to confirm or refute the diagnosis, and enable reduced time to treatment. They have reported a reduction in incidence of GCA-related sight loss $[14,15]$. Those that present with new visual loss (transient or permanent) or double vision should be evaluated as soon as possible on the same calendar day by an ophthalmologist. Patients without ophthalmic symptoms should be seen within 3 working days by a specialist with the appropriate expertise. Where GCA is strongly suspected by the referrer, glucocorticoids should be prescribed without waiting for test results $[10,11]$.

\section{Recommendations for serological investigations}

There were no changes to the recommendations of the diagnostic blood tests for GCA, which include an ESR, CRP and platelet count. If ESR is unavailable, plasma viscosity can be used instead. 
Fig. 12020 British Society for Rheumatology Giant Cell Arteritis guidelines infographic summary. The key aims, recommended tests for diagnosis, treatments and long-term managment are highlighted.

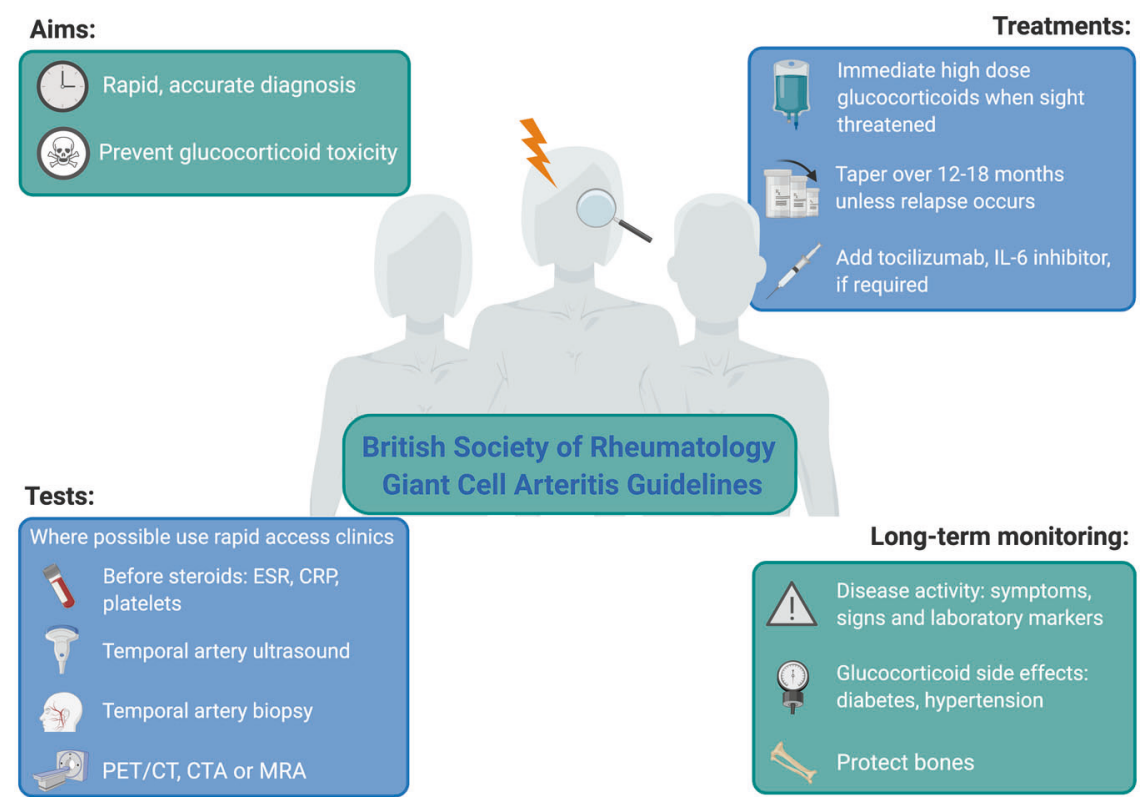

The guidelines recommended that within 2 weeks of diagnosis the prescriber of glucocorticoid therapy ensures the patient is assessed for glucocorticoid-related complications including hypertension and hyperglycaemia. Other risks associated with glucocorticoid therapy such as infection and fracture should be managed using existing local or national guidelines (Fig. 1).

\section{Recommendation for a confirmatory investigation}

The major change in this guidance is now a strong recommendation for a confirmatory test: $\mathrm{TAB}$, temporal artery ultrasound, or both (Fig. 1) [10, 11]. Anecdotal practice to date suggests that some were diagnosed based on history, examination and laboratory tests alone; this could potentially lead to overdiagnosis. Ultrasound imaging of the temporal and axillary arteries was found to be more sensitive but less specific than TAB for the diagnosis of GCA [6]. In the UK, the most cost-effective strategy incorporates ultrasound for all patients and TAB for a subset where the diagnosis is still unclear [6]. In patients with large-vessel involvement further imaging tests may be useful to demonstrate inflammation of the aorta or its proximal branches (Fig. 1).

\section{Recommendations in acute sight threatening disease}

Immediate action is required should someone suspect sight threatening GCA, this also includes those with acute double vision attributed to GCA. If intravenous glucocorticoid is not possible, $60-100 \mathrm{mg}$ oral prednisolone may be given for up to 3 consecutive days, prior to a long-term taper (Fig. 1). This was a conditional recommendation as only observational data is available; the majority of visual loss in GCA occurs before initiation of glucocorticoid treatment [4].

\section{Recommendations for long-term management}

Providing there is no return of GCA symptoms, signs or laboratory markers of inflammation, there is a conditional recommendation of a 12- to 18-month taper of glucocorticoid to cessation of therapy. Many patients require substantially longer than this, due to relapse. Glucocorticoid toxicity is a key concern [16]. A conditional recommendation was made for the use of methotrexate as a glucocorticoid sparing therapy in patients at high risk of glucocorticoid toxicity or who relapse. This was made on the basis of three historical randomized controlled trials (RCT), where the evidence for methotrexate as a glucocorticoid sparing agent remains equivocal: these trials were performed using low dose methotrexate. Other immunosuppressants (including azathioprine, leflunomide and mycophenolate) have not been adequately tested in clinical trials to permit recommendations.

There was a strong recommendation for the use of the biologic therapy, tocilizumab, an IL-6 receptor antagonist, in combination with a glucocorticoid taper, which is based on two RCTs which led to regulatory approval $[17,18]$. Currently a time limited duration of tocilizumab for GCA has been approved in Scotland and by NHS England for 
defined patient groups (relapsing or refractory GCA). At present, in England, it is difficult to access tocilizumab therapy for those without biopsy or imaging confirmation of their GCA diagnosis, underlining the importance of pursuing a confirmatory test.

\section{Conclusions}

Many questions remain and there is currently interest in novel therapies targeted at different points in the immunological pathway $[8,16]$. It remains to be seen which groups benefit the most from immunomodulatory therapy and how long treatment should last. Future predictive biomarkers are sought to identify those who subsequently have stormy disease course, and indeed for a very small number who have visual loss much later in their disease course [19].

Given rheumatologists' expertise in GCA, their experience of using TCZ in other rheumatological conditions such as rheumatoid arthritis and their ultrasound skills, rheumatologists are invaluable in the diagnosis and long-term management of GCA. Ophthalmology should actively support their rheumatology colleagues in providing quick open access to $\mathrm{TAB}$ for the reduced numbers of surgeries now required for those with or without visual symptoms of GCA.

Funding SPM: none. OG is funded by a Brain Research UK PhD Studentship. EO'S: none. SLM receives infrastructure support from the MRC TARGET Partnership Grant (MR/N011775/1/MRC_/Medical Research Council/United Kingdom).

\section{Compliance with ethical standards}

Conflict of interest SPM has received advisory board and speaker fees from Roche (2016-2019); speaker fees from Chugai-Roche Ltd (2017-2019) and advisory board fees from Janssen (2020). She has acted as investigator on a clinical trial in GCA for Roche. OG has no conflicts of interest relating to the subject matter. EO'S received consultancy fees from Roche (2015). SLM received consultancy fees from Roche (2015) and was supported by Roche to attend EULAR 2019. She has acted as investigator on clinical trials in GCA for Sanofi, Roche and GSK. Consultancy fees from Roche $(2016,2018)$ and Sanofi (2017) were paid to her institution. She is Patron of the UK charity PMRGCAuk.

Publisher's note Springer Nature remains neutral with regard to jurisdictional claims in published maps and institutional affiliations.

\section{References}

1. Lyons HS, Quick V, Sinclair AJ, Nagaraju S, Mollan SP. A new era for giant cell arteritis. Eye. 2020;34:1013-26.

2. Hayreh SS, Podhajsky PA, Zimmerman B. Occult giant cell arteritis: ocular manifestations [published correction appears in
Am J Ophthalmol 1998 Jun;125(6):893]. Am J Ophthalmol. 1998;125:521-6.

3. Martins P, Teixeira V, Teixeira FJ, et al. Giant cell arteritis with normal inflammatory markers: case report and review of the literature. Clin Rheumatol. 2020. https://doi.org/10.1007/s10067020-05116-1.

4. González-Gay MA, García-Porrúa C, Llorca J, et al. Visual manifestations of giant cell arteritis. Trends and clinical spectrum in 161 patients. Medicine. 2000;79:283-92.

5. Mackie SL, Brouwer E. What can negative temporal artery biopsies tell us? Rheumatology. 2020;59:925-7.

6. Luqmani R, Lee E, Singh S, et al. The role of ultrasound compared to biopsy of Temporal Arteries in the Diagnosis and Treatment of Giant Cell Arteritis (TABUL): a diagnostic accuracy and cost-effectiveness study. Health Technol Assess. 2016;20:1-238.

7. Best JH, Kong AM, Unizony S, Tran O, Michalska M. Risk of potential glucocorticoid-related adverse events in patients with giant cell arteritis: results from a USA-based electronic health records database. Rheumatol Ther. 2019;6:599-610.

8. Al-Mousawi AZ, Gurney SP, Lorenzi AR, et al. Reviewing the pathophysiology behind the advances in the management of giant cell arteritis. Ophthalmol Ther. 2019;8:177-93.

9. Mollan SP, Begaj I, Mackie S, et al. Increase in admissions related to giant cell arteritis and polymyalgia rheumatica in the UK, 200213, without a decrease in associated sight loss: potential implications for service provision. Rheumatology. 2015;54:375-7.

10. Mackie SL, Dejaco C, Appenzeller S, et al. British Society for Rheumatology guideline on diagnosis and treatment of giant cell arteritis. Rheumatology. 2020;59:e1-23.

11. Mackie SL, Dejaco C, Appenzeller S, et al. British Society for Rheumatology guideline on diagnosis and treatment of giant cell arteritis: executive summary. Rheumatology. 2020;59:487-94.

12. Dasgupta B, Borg FA, Hassan N, et al. BSR and BHPR guidelines for the management of giant cell arteritis. Rheumatology. 2010;49:1594-7.

13. Schünemann HJ, Oxman $\mathrm{AD}$, Brozek J, et al. Grading quality of evidence and strength of recommendations for diagnostic tests and strategies [published correction appears in BMJ. 2008 May; 336. https://doi.org/10.1136/bmj.a139. Schünemann, A Holger J [corrected to Schünemann, Holger J]]. BMJ. 2008;336:1106-10.

14. Patil P, Williams M, Maw WW, et al. Fast track pathway reduces sight loss in giant cell arteritis: results of a longitudinal observational cohort study. Clin Exp Rheumatol. 2015;33(2 Suppl 89): S-103-6.

15. Diamantopoulos AP, Haugeberg G, Lindland A, Myklebust G. The fast-track ultrasound clinic for early diagnosis of giant cell arteritis significantly reduces permanent visual impairment: towards a more effective strategy to improve clinical outcome in giant cell arteritis? Rheumatology. 2016;55:66-70.

16. Coath F, Gillbert K, Griffiths B, et al. Giant cell arteritis: new concepts, treatments and the unmet need that remains [published correction appears in Rheumatology (Oxford). 2019 Jul 1;58 (7):1316]. Rheumatology. 2019;58:1123-25.

17. Stone JH, Tuckwell K, Dimonaco S, et al. Trial of Tocilizumab in Giant-Cell Arteritis. N Engl J Med. 2017;377:317-28.

18. Villiger PM, Adler S, Kuchen S, et al. Tocilizumab for induction and maintenance of remission in giant cell arteritis: a phase 2, randomised, double-blind, placebo-controlled trial. Lancet. 2016;387:1921-7.

19. Liu GT, Glaser JS, Schatz NJ, Smith JL. Visual morbidity in giant cell arteritis. Clinical characteristics and prognosis for vision. Ophthalmology. 1994;101:1779-85. 